CASE REPORT

\title{
A Reflective Journey of Caring : A Case Study Between A Patient with Schizophrenia and the Interdisciplinary Team
}

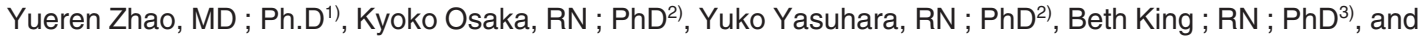 \\ Tetsuya Tanioka, RN ; PhD, FAAN ${ }^{2}$ \\ ${ }^{1)}$ Department of Psychiatry, School of Medicine, Fujita Health University, Aichi, Japan, ${ }^{2)}$ Department of Outcome management, Graduate \\ School of Biomedical Sciences, Tokushima University, Tokushima, Japan., ${ }^{3)}$ Christine E Lynn, College of Nursing, Florida Atlantic \\ University, Florida, USA
}

\begin{abstract}
This case study focuses on caring for a patient living with schizophrenia who has been isolated from the community caused by long-term hospitalization in Japan. Using the philosophical perspective of caring, which focuses on nurturing the wholeness and well-being of persons in caring relationship, the case study illuminates the caring, empathy, and courage among the interdisciplinary team. The purpose of this case study is to discuss the interdisciplinary caring process for patients living with schizophrenia using Carper's ways of knowing. Personal knowing is presented through the lens of patients and families and the stigma associated with mental illness. The expression of respect and caring for the patient and their families led by the interdisciplinary team aided in destigmatization of mental illness. Empirical and ethical knowing is demonstrated through the mental health care team's delivery of high quality and clinical excellence with competence, compassion and caring. Aesthetic knowing was offered by the interdisciplinary team focused on the patient's underlying hopes, dreams and aspirations. Through the support of the interdisciplinary team, patients are able to move toward their goals, hopes and dreams, externalizing tasks, as they grow together through mutual caring. J. Med. Invest. 66 : 15-18, February, 2019
\end{abstract}

Keywords : Caring, Ways of Knowing, Stigma, Interdisciplinary Collaboration, Psychiatry

\section{INTRODUCTION}

Involuntary long term hospitalization for persons living with mental illnesses is frequently related to treatment challenges such as disease severity and adherence to treatment (1). Tachimori et al. (2) points out that the national discharge rate for long-term patients was higher in 2012 than in 1999 and was trending toward the target goal throughout the 2000s, but the goal has not yet been met. As for discharge rates of long-term admissions in local communities, some problems remain to be solved in order to achieve the goals of the reform vision. Kanata (3) reports that mental health care has been shifting from psychiatric institutions towards communitybased settings for the last 40 years in most countries. However, Japan still has a very high ratio of psychiatric care beds per capita, and the average length of stay in psychiatric institutions is nearly 300 days.

In the attempt to increase the number of discharged patients and reduce the number of psychiatric beds, the nature of the problem must be analyzed, and facilitation of effective rehabilitation must take in consideration of places where persons with mental disorders live. Temporary solutions to the problem can only result in temporary fixes (4).

The focus on discharge, has resulted in many challenges. Discharge, after long-term hospitalization results in many challenges for both the person living with mental illness and health care professionals. It is no easy feat for persons with mental illnesses to

Received for publication October 31, 2018 ; accepted November 1, 2018.

Address correspondence and reprint requests to Zhao Yueren, MD, PhD,1-98 Dengakugakubo, Kutsukake-cho, Toyoake, Aichi 470-1192, Japan and Fax : +81-562-93-1831. re-start their social lives in their community, especially with the social stigma associated with mental illness. Thus, sharing the goal of reducing mental-health-related stigma would contribute not only to maintaining activities tackling against stigma of mental illness but also to developing community care.

A basic caring attitude is a requisite condition to resolving these issues : i.e., endeavoring to fully understand patients and their circumstances, and to provide them with the proper support so they can achieve the outcome they hope for. Stigmatic beliefs held by families, patients, and medical professionals can be confronted through therapeutic dialogue to establish and pursue shared treatment goals.

The purpose of this study is to discuss the interdisciplinary caring process for a patient living with schizophrenia over a 4 year period, using a caring-based model to analyze his recovery process.

\section{METHODS}

Analytic framework: Carper's (1978) fundamental ways of knowing in nursing were adopted as a caring-based model to analyze the recovery process $(5,6,7)$. In healthcare, Carper's fundamental ways of knowing is a typology that attempts to classify the different sources from which knowledge and beliefs in professional practice (originally specifically nursing) can be or have been derived. The typology identifies four fundamental "patterns of knowing": Personal : Knowledge and attitudes derived from personal selfunderstanding and empathy, including imagining one's self in the patient's position. Empirical : Factual knowledge from science, or other external sources, that can be empirically verified. Ethical : Attitudes and knowledge derived from an ethical framework, including an awareness of moral questions and choices. Aesthetic: 
Awareness of the patient as a whole, including awareness of the patient and their circumstances as uniquely individual, and of the combined wholeness of the situation.

Case : The patient was a man in his 50 s born in Japan, without any intellectual or developmental abnormalities. He entered the working world soon after graduating from junior high school. He was diagnosed with schizophrenia during a 10-year prison sentence following several serious crimes committed in his 20 s. Citing unintelligible speech and irrational behavior, the prison warden advised that he be committed to a private hospital specializing in psychiatric care in accordance with Japan's Act on Mental Health and Welfare for the Mentally Disabled; which resulted in a forced hospitalization order from the prefectural governor. Due to violent behavior to other inpatients, he was housed in an isolation room for the majority of his over-10-year stay. Reminiscent of a prison cell, this room was a source of trauma for the patient. Unhappy with his therapy and very reluctant to play any role in it, he displayed an uncooperative attitude towards medical staff and other members of the interdisciplinary care team. It was difficult for the attending psychiatrist to give instructions to release him from the seclusion room, because when he got out of the seclusion room. He was very distrustful of others and in a short period of time, and he became irritated and violent at trivial remarks and actions. Medication therapy was necessary for his release from the seclusion room, along with a comprehensive understanding by the nurses that he was person with an unstable mental condition.

Treatment approach and course : Therapy consisted of daily nonverbal interactions (e.g. pulse measurements) and regular dialogue in a goal-sharing meeting with an interdisciplinary care team. The objectives were not only recovery from the symptoms of the disease, but also the restoration of self-efficacy and treatment motivation and, eventually, his release from hospital.

Initially, the patient completely ignored his psychiatrists, and would not engage productively in the goal sharing meetings. It took approximately two years for him to allow his pulse to be taken, to exchange simple greetings, and to participate productively in the consultations, problem-solving, and other activities with the interdisciplinary care team. He was successfully released from hospital after about four years of treatment in total.

Ethical considerations : The patient signed a consent form after being explained verbally and in writing that our case report would conceal his personal information to protect his privacy. Approval from the Ethics Committee of his admitting hospital was also obtained.

\section{RESULTS}

Personal: The patient was resistant to treatment for nearly the first two years, scarcely allowing staff to take his temperature and pulse and ignoring his attending physician even when greeted. His attitude underwent a gradual transformation as the daily pulsetaking and greetings continued. One morning, the patient uttered something connected to the official treatment goal: "Let me out of here!"

His doctor concluded that at the heart of these words lay a positive message : that this patient, harsh and violent at first glance, wanted to pursue recovery in the form of living freely the same as others and becoming happier. This was the moment that the 'seed of recovery' was planted in the soil of dialogue.

Even though the mother had the desire to return her son with mental illness back to her house, it was thought that his mother was also considering that there were local residents who felt uncomfortable for the person who had a criminal record with mental illness. His mother expressed through her letter to his attending psychiatrist that "my son has no choice but to stay in the hospital for the rest of his life." It was inferred that the social stigma for the person with mental illness was related to the background of the stigma from the family believe his son's illness cannot be recovered and discharged.

Empirical: With the aid of the interdisciplinary care team, the patient set up a personal goal map for himself, plotting his longterm goal as living together with a (romantic) partner in the community without schizophrenia recurrence, and his short-term goal as being released from hospital and living alone. The goals needed to fulfill four conditions : they needed to be 1) be specific and feasible, 2) not too easy, 3) something the patient genuinely wished to work towards, and 4) able to be modified at any time upon consultation with the interdisciplinary team. The patient received social skills training to overcome the various hurdles in the way of his short- and long-term goals, as well as psychological education aimed at ensuring his mental health as he lived a normal life in the community.

Through repeated discussions, the patient and interdisciplinary team agreed that his treatment should focus on the short-term goals while he was still in the hospital : "achieving a normal life in his community with the support of a team composed of different healthcare professionals". The specific approaches followed by the interdisciplinary care team can be summarized as the three therapeutic approaches below.

Approach 1 - Psychopharmacological treatment: Patient had been treated with antipsychotic polypharmacy for over ten years aimed at reducing violent behavior, agitation, hallucinations, and delusions. As a result, he had long suffered side effects including oversedation, extrapyramidal symptoms, and sexual dysfunction. To alleviate these problems, his doctor proposed he be switched to atypical antipsychotic monotherapy slowly over time, which is simpler and has fewer side effects than polypharmacy. With the help of the pharmacist, we explained the safety, efficacy, suitability, and costs of risperidone injectable treatment using plain language that the patient could understand. Injection monotherapy-one intramuscular injection every two weeks-was selected in the hopes of improving medication adherence, and continued therapeutic effects : namely, mild improvement in positive symptoms, primarily the hallucinations and delusions.

Approach 2 - Goal-sharing meetings: These meetings were held regularly with the aim of ensuring the patient and interdisciplinary team were on the same page about his treatment goals. Initially, he would get up from his seat after about five minutes, ending the meeting, but eventually these weekly sessions would come to last a full 30 minutes. In addition to the meetings' core members (i.e., the patient and his attending physician and nurse), other professionals would be invited as needed. For example, a psychiatric social worker attended meetings when the patient needed education and assistance about social resources to help him live by himself. Meetings began with a simple warm-up exercise, and enlisted a variety of psychosocial techniques such as cognitive behavioral therapy and social skills training. Over time, the patient's conduct became consistent enough to support an action cycle. Namely, the patient would take notes during each meeting on the goals and details of his treatment, his own commitments, and positive feedback from the different staff in attendance. Then, members of the interdisciplinary team used those notes to design a support plan to meet their own commitments to the patient, and put the corresponding measures in place by the time of the next meeting.

Approach 3 - Onsite rehabilitation: Rehabilitation activities necessary to achieve the treatment goals reached in the goal sharing meeting were performed both inside and outside the hospital with the help of the interdisciplinary team. For example, a nurse would go with him as he tried to ride local buses, which would be his means of transport in his community, a nutritionist and occupational therapist would give him advice about cooking in preparation 
for living alone and nursing assistants would show him how to clean and do laundry.

Ethical : When considering the primary causes behind someone's long-term institutionalization in a psychiatric hospital or isolation treatment, people have an unfortunate tendency to ascribe these situations to patient-centric factors such as the severity of their illness or personality. We did not simply provide our patient with knowledge about his disease and treatment; we actively tried to engage him in his treatment plan ; repair of his relationship with his family, with whom he had become estranged as a result of his long institutionalization, and engaged in information sessions about social resources to help him restart his life in the community, with the goal of maintaining his dignity. We first suggested a face-to-face meeting with his mother, his only remaining family member. It was sometimes difficult to reach consensus : recalcitrant and obstinate, his opinions and values of this patient were often at odds with the team's. However, confronting patients with contrasting opinion and value judgments is precisely the goal of therapeutic dialogue, so we persevered to continue the dialogue, with occasional diversions.

Slowly over time, we helped the patient and his mother to reach an understanding, aiming to restart his social life after discharge. A psychiatric social worker helped him with issues such as securing a place to live after discharge and encouraging the utilization of social resources. A pharmacist, psychiatric occupational therapist, psychologist, and dietician applied social skills training (SST) to educate him on matters related to solitary living such as medication adherence, cooking, laundry, and cleaning, tailoring the training to accommodate his comprehension ability and pace. Throughout, they verified that the patient was willing to participate in his treatment, despite his low self-esteem resulting from long-term hospitalization and isolation.

Aesthetic: The patient's mother wrote him and his attending doctor a letter after he was released from prison and institutionalized (excerpted below).

"I'm going to be 90 this year. I can't take care of you anymore. I would be happy if you listened to what your attending doctor says, and stay in hospital. Please [Dr. M.], keep my son in hospital."

Advancing age is a problem that can affect people with mental illnesses and their families alike. In this letter, the patient's mother divulged her innermost, painful feelings, saying that her weak stamina and physical frailty made it difficult for her to meet him at hospital.

To rebuild their tenuous relationship, nurses suggested helping the patient to write a letter to his mother. He initially refused, claiming he was no good at writing, but started to show interest when the nurses repeatedly demonstrated in front of him how to write a model reply. A few months later, he was writing and sending off a postcard every month.

His correspondence with his mother lasted several years, up until his discharge from hospital. One day, the patient received the letter below (excerpted in part).

"You seem so happy every day, that's great. Listen well to what your doctors and nurses say : you'll have to keep doing your best after you leave. -Mom”

He read this letter aloud to his doctors and nurses over and over again, expressing his belief that her exhortation to keep doing his best meant that she had finally come to accept his release, despite her initial opposition. This high point was the product of several, interlocking positive forces : slight remission of symptoms due to pharmacotherapy, improved communication skills thanks to psychosocial therapy, and the implementation of caring practices (primarily by nurses) to cultivate a desire to receive treatment in the patient.

Through this written correspondence, maternal feelings were reawakened in his mother, who had once rejected the notion that her son could be safely discharged, leading her to come to accept her son's feelings, and know them in an aesthetic way.

\section{DISCUSSION}

Psychosocial treatment: We followed a patient-centered, multidisciplinary team approach to establish a dialogue with our patient. Using the tool of a personal goal map (8), the patient dissected and identified specific treatment goals, and he was rewarded by a sense of accomplishment as he reached one goal after the other. Our approach was successfulin reducing his self-stigma, allowing him to set personalized treatment goals, and helping him to restart his life in the community, an outcome that had once seemed impossible.

Social stigma mediated our therapy's course and success throughout the four-year process from its start to discharge. The following analysis identifies several assumptions and preconceptions held by the patient, his mother, and the interdisciplinary staff that affected his long-term institutionalization and sense of isolation as well as the corresponding solutions.

Stigmatic beliefs of patient and family: This patient's despondency and anguish at being forcibly committed to a psychiatric hospital due to mental illness immediately after completing his 10 -year prison sentence, and facing new restrictions on his freedom of movement and activities are impossible to fathom. Involuntary commitment is grounded in Japanese law : we believe that it was the right measure to take based on his severe condition at the start of treatment. However, his prolonged hospitalization and behavioral restrictions left the patient deeply distrusting of medical staff. Preconceptions about his own fate, such as perhaps never being able to leave the hospital, or even isolation room, were major obstacles preventing the seed of recovery from sprouting.

Other contributing factors included his poor understanding of his illness, and his failure to appreciate the significance of returning to the community after finishing his sentence. The stigma associated with mental illness harms the self-esteem of many people who have serious mental illnesses (9). Stigma is evident in the way laws, social services, and the justice system are structured as well as ways in which resources are allocated (10). An important consequence of reducing stigma would be to improve the selfesteem of people who have mental illnesses. Stigmatized families could experience negative emotional consequences, such as fear, anxiety, guilt, shame, worry, intense concern, and a sense of desperation. In addition, they might experience a variety of social consequences, such as discrimination, losing their job or housing, gaining a bad reputation, or feeling family burden (11).

His mother's anguished belief that it would now be impossible for her son to leave the hospital and live in the community, despite her immense pity for the suffering he endured as a result of his mental illness and long-term hospitalization, was also another obstacle standing in the way of the patient's recovery.

Solutions for patient and family: In order to reduce the patient's distrust of medical professionals, we needed to continue the therapeutic dialogue for many years as we went about our daily interactions (pulse-taking, greetings), to repeatedly communicate the message that it is possible to recover from schizophrenia. The patient was ecstatic when he completed even small challenges necessary for his recovery, such as when he practiced writing letters to his mother. In addition, he even gained the understanding and cooperation of his elderly mother, who was unable to visit him in hospital directly, by persevering in communicating the 
details of his recovery in his own words, through the sole means of written correspondence.

Converging historical events, new biogenetic research findings ; widening recognition of the dimensions of family burden ; deinstitutionalization, have led to a reconceptualization of the family role (12). It should go without saying that mental health professionals must be flexible when promoting the patient-family relationship and their options for communication when devising a treatment plan.

Stigmatic beliefs of psychiatrists : Stigma is defined as a sign of disgrace or discredit, which sets a person apart from others. The stigma of mental illness, although more often related to context than to a person's appearance, remains a powerful negative attribute in all social relations (13). Many psychiatrists are quick to believe the stereotypical assumption that it is difficult to quickly discharge patients with intractable schizophrenia. Several misconceptions initially surrounded his care ; the beliefs that intractable schizophrenia made polypharmacy unavoidable, and that he wouldn't respond well to any new medications. Other deep-seated assumptions regarded matters other than his medical care, especially his criminal history, and the belief that having caused serious problems in the community, it would be impossible to rehabilitate the offender into society, at least immediately, and that staff's words would not get through to a recalcitrant, violent, former criminal.

Solutions for the mental health care team: Simply supplying the interdisciplinary care team with the right knowledge of psychiatric concepts is not enough to correct mistaken assumptions. It is necessary to learn about respect for fundamental human rights, a principle enshrined in both the Japanese Constitution and the United Nations' Principles for the Protection of Persons with Mental Illness (MI Principles) (14). In addition, one specific task that staff should adopt is to challenge patients with contrasting opinions during therapeutic dialogue and meeting sessions. Moreover, hospital staff gradually revised their biases and beliefs after seeing the patient's attitude change as a result of such dialogue with their own eyes.

\section{CONCLUSION}

This retrospective examination of the treatment process using the framework of Carper's four ways of knowing supports how the attitude and actions of the interdisciplinary team were patientcentric and deeply rooted in caring. Patients, families and mental healthcare professionals need to constantly pay attention to their own beliefs and stigma. The interdisciplinary team has to demonstrate compassion and caring while delivering high quality and clinical excellence. In addition, knowing the patient's underlying hopes, dreams and aspirations facilitate the accomplishment of patient goals. Most importantly, the interdisciplinary team's supportive care provides maintenance of motivation for patient to achieve goals, externalizing tasks and growing together during care.

\section{CONFLICT OF INTEREST}

There is no actual or potential conflict of interest that exist in this manuscript

\section{REFERENCES}

1. Testa M, West SG : Civil Commitment in the United States. Psychiatry (Edgmont) 7(10) : 30-40, 2010

2. Tachimori H, Takeshima T, Kono T, Akazawa M, Zhao X: Statistical aspects of psychiatric inpatient care in Japan : Based on a comprehensive nationwide survey of psychiatric hospitals conducted from 1996 to 2012. Psychiatry Clin Neurosci 69(9) : 512-22, 2015

3. Kanata T: Japanese mental health care in historical context : why did Japan become a country with so many psychiatric care beds?. Social work (Stellenbosch. Online) 52 (4) : 471-489, 2016

4. Ando S, Yamaguchi S, Yuta Aoki Y, Thornicroft G : Review of mental-health-related stigma in Japan. Psychiatry and Clinical Neurosciences 67 : 471-482, 2013

5. Carper B : Fundamental patterns of knowing in nursing. Adv Nurs Sci1(1) : 13-23, 1978

6. Patricia E : Zander, Ways of Knowing in Nursing : The Historical Evolution of a Concept. The Journal of Theory Construction \&Testing 11(1) : 7-11, 2007

7. Christopher J : Framing learning through reflection within Carper's fundamental ways of knowing in nursing. Journal of Advanced Nursing $22: 226-234,1995$

8. Zhao Y : The Power of Personal Goal Sharing. -People with Mental Disorders Turning Plans into Action Using Personal Goal Maps-. Psychiatria et Neurologia Japonica 113(10) : 1028-1033, 2011

9. Link BG, Struening EL, Neese-Todd S, Asmussen S, Phelan JC : Stigma as a Barrier to Recovery : The Consequences of Stigma for the Self-Esteem of People With Mental Illnesses. Psychiatric services 52(12) : 1621-1626, 2001

10. Corrigan PW, Watoson AC : Understanding the impact of stigma on people with mental illness. World Psychiatry 1(1) : 16-20, 2002

11. Park S, Park KS : Family Stigma : A Concept Analysis. Asian Nursing Research 8(3) : 165-171, 2014

12. Lefley HP : Family burden and family stigma in major mental illness. American Psychologist 44(3) : 556-560, 1989

13. Byrne P : Stigma of mental illness and ways of diminishing it. Advances in Psychiatric Treatment 6(1) : 65-72, 2000

14. World Health Organization : Mental Health Policy and Service Guidance Package : Mental health legislation and human rights. Geneva, 2003

http : //www.who.int/mental_health/policy/services/7_ legislation\%20HR_WEB_07.pdf 